Iran Journal of Nursing (IJN)

Vol 32, No. 118, Jun 2019: 93- 103

\title{
Self-care Agency and Its Influential Factors in Hemodialysis Patients
}

\author{
Mostafa Soodmand ${ }^{1}$, Golshan Ghasemzadeh ${ }^{2}$, Samaneh Mirzaei Dahka ${ }^{3}$, \\ Mohsen Mohammadi ${ }^{4}$, Nasim Amoozadeh Lichaei ${ }^{5}$, Arezoo Monfared $^{6}$
}

\begin{abstract}
Background \& Aims: Chronic kidney disease is a destructive and irreversible process, which reduces glomerular filtration, decreases the ability of the kidneys to retain fluids and electrolytes, and disrupts water and urea balance, thereby leading to uremia. This disease is accompanied by constant hospitalization, reduced quality of life, high mortality, and extreme medical costs. End-stage kidney disease refers to the irreversible loss of the renal function, in which case the kidneys are unable to support the life of the patient, and kidney transplantation is considered to be the treatment of choice. Due to the unevenness of this process, the majority of the patients in the world must remain under hemodialysis treatment until the kidney transplant is performed. Today, hemodialysis is a common treatment for chronic kidney failure. The patients receiving hemodialysis experience limitations in their physical, mental, and social functioning and self-care activities in patients; this could play a key role in their adaptation to the disease process, improving the quality of life, and reducing the number of hospitalizations, length of hospital stay, treatment costs, and mortality. Given the importance of selfcare in hemodialysis patients and the need for care and treatment planning, the present study aimed to assess the ability of self-care and its influential factors in hemodialysis patients.

Materials \& Methods: This cross-sectional study was conducted with the permit of the Ethics Committee of Guilan University of Medical Sciences, Iran (IR.GUMS.REC.1395.310), starting in January 2016 until November 2017. The sample population included the patients referring to the hemodialysis ward of Razi Hospital in Rasht, who were selected via simple random sampling. Based on the Morgan table, the number of the sample was determined per 187 dialysis patients at this center to be 126. In order to compensate for the possible loss of the patients, 137 patients were enrolled in the study. During the study, four patients were excluded due to unwillingness to continue participation, and seven patients were excluded due to weakness and lethargy while completing the questionnaire; finally, 126 patients were evaluated. The inclusion criteria were the age of 18-75 years, ability in self-care, minimum dialysis history of three months, willingness to participate, and absence of physical and motor disabilities, mental retardation, and mental disorders. The exclusion criteria were weakness, lethargy, restlessness, and withdrawal from the study. Data were collected using a questionnaire consisting of two sections; the first section included individual-social data, and the second section was the modified form of the 28-item Chinese version of the self-care ability assessment, scored based on a five-point Likert scale (Not at All=1, Rarely=2, Usually=3, Often=4, Always=5). The final score was within the range of
\end{abstract}

1. MS in Internal-Surgical Nursing, Student Research Committee, Shahid Beheshti School of Nursing and Midwifery, Guilan University of Medical Sciences, Rasht, Iran

2. BS in Nursing, Student Research Committee, Shahid Beheshti School of Nursing and Midwifery, Guilan University of Medical Sciences, Rasht, Iran

3. MS Student in Nursing, Student Research Committee, Shahid Beheshti School of Nursing and Midwifery, Guilan University of Medical Sciences, Rasht, Iran

4. MS Student in Nursing, Student Research Committee, School of Nursing and Midwifery, Ardebil University of Medical Sciences, Ardebil, Iran

5 . BS Student in Nursing, Student Research Committee, Shahid Beheshti School of Nursing and Midwifery, Guilan University of Medical Sciences, Rasht, Iran

6. PhD. Candidate in Nursing, Guilan University of Medical Sciences, Lecturer, Department of Nursing, Islamic Azad University, Rasht Branch, Rasht, Iran (Corresponding author) Tel: +98 (911) 3479959

Email: a.monfared88@gmail.com 
28-140, and the higher score than 84 indicated desirable self-care ability. The reliability of the tool has been confirmed using the test-retest method at the Spearman's correlation-coefficient of 0.85 and internal consistency at the Cronbach's alpha of 0.83 in previous studies. The reliability of the instrument in the present study was obtained with 20 pilot samples at the Cronbach's alpha of 0.80. Data analysis was performed in SPSS version 16 using descriptive statistics (mean, frequency, percentage) and analytical tests (independent t-test, correlationcoefficient, analysis of variance, and logistic regression).

Results: The mean age of the participants was $54.9 \pm 16.1$ years, and the mean duration of hemodialysis was $35.72 \pm 33.35$ months. The mean score of self-care capacity in the patients was $94.63 \pm 21.57$, and $71.4 \%$ of the patients had optimal self-care capacity. No significant correlation was observed between gender and self-care capacity, while men had a higher mean self-care score compared to women. Pearson's correlation-coefficient indicated an inverse, significant correlation between age and self-care ability, so that the older patients had lower self-care capacity $(\mathrm{P}=0.013 ; \mathrm{r}=-0.22)$. In addition, a significant association was denoted between education level and self-care capacity based on the variance analysis, so that the patients with higher education levels had a higher self-care ability $(\mathrm{P}<0.0001 ; \mathrm{F}=9.53)$. No significant associations were observed between smoking habits and alcohol consumption, marital status, and duration of hemodialysis with the self-care capacity of the patients. Based on the multivariate regression model and using the backward method, the results indicated that age was an important influential in the factor reduction of the self-care capacity of the hemodialysis patients, and the increased age of the patients than the total mean age was associated with their lower self-care ability by 1.5 times $(\beta=-0.786 ; \mathrm{df}=1 ; \mathrm{RR}=0.456 ; \mathrm{CI}=0.204-1.018)$.

Conclusion: Although the majority of the patients undergoing hemodialysis had favorable self-care capacity, the findings indicated that these patients faced limitations in self-care due to aging, the treatment process, and the problems resulting from the disease. Given the importance of self-care in improving the conditions of patients and preventing and controlling the complications of diseases and treatment methods, it is recommended that educational and counseling measures appropriate to the age of patients be taken in their care program in order to improve their self-care capacity, so that they would be fully involved in self-care as a member of the healthcare team. In addition, nurses should take steps toward educating patients individually as an important nursing task by applying the necessary changes in the training programs for hemodialysis patients in order to change the state of self-care in these patients.

Keywords: Self-care Agency, Hemodialysis, Chronic Renal Disease

\section{Conflict of Interest: No}

How to Cite: Soodmand M, Ghasemzadeh G, Mirzaei Dahka S, Mohammadi M, Amoozadeh Lichaei N, Monfared A. Self-care Agency and Its Influential Factors in Hemodialysis Patient. Iran Journal of Nursing. 2019; 32(118):93-103.

Received: 19 March 2019

Accepted: 22 Jun 2019 


\title{
بررسى توان خودمر اقبتى و عوامل مرتبط با آن در بيماران همودياليزى
}

\author{
مصطفى سودمند'، كَلشن قاسم زاده '، سمانه ميرزايى دهكآ، محسن محمدى

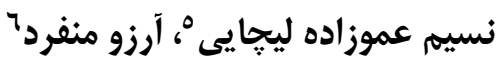

\begin{abstract}
جكيله
زمينه و هدف: امروزه همودياليز يكى از رايجترين روشهاى درمانى به دنبال نارسايى مزمن كليه مى باشد. بيمـاران تحـت درمـان بـا هموديـاليز دجـار

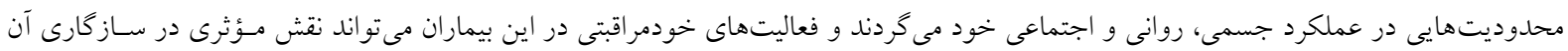

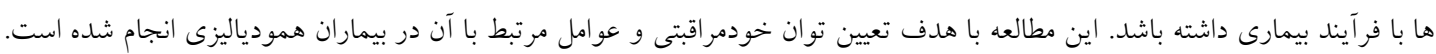

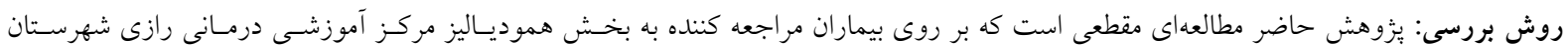

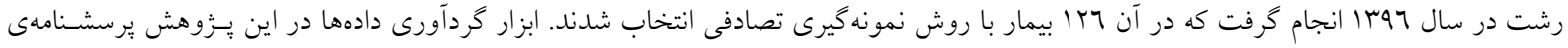

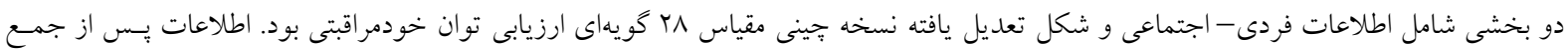

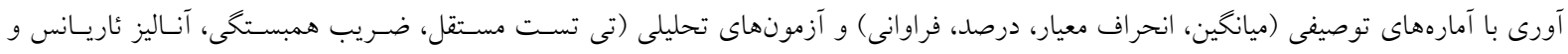
ركرسيون لجستيك) مورد تجزيه و تحليل قرار خرفت.
\end{abstract}

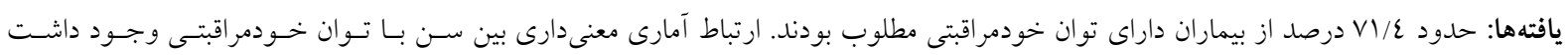

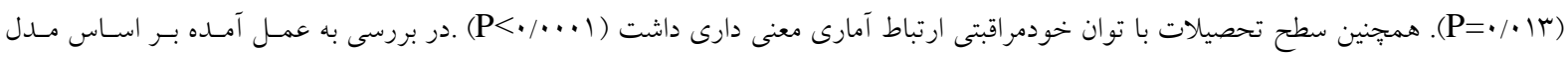

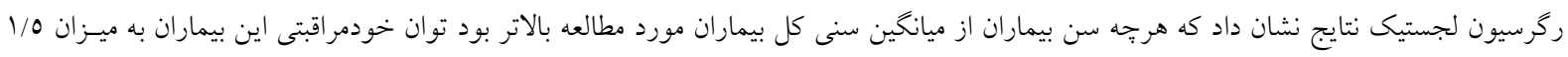
برابر كاهش بيدا كرده بود. نتيجه گيرى كلى: اكر جه در مطالعهى حاضر بيشتر بيماران تحت درمان با همودياليز داراى توان خودمراقبتى مطلوبى بودند اما نتايج ايسن مطالعه نشـان

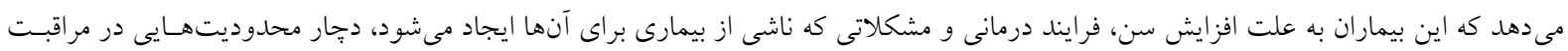

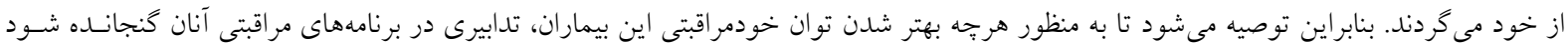

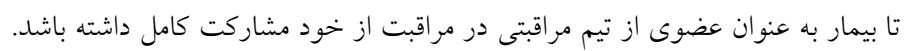

كليل وازهها: توان خودمراقبتى، همودياليز، نارسايى مزمن كليه

تعارض منافع: ندارد

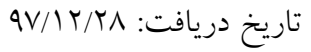

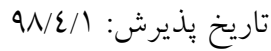

'. كارشناسى ارشد يرستارى داخلى و جراحى، كميته تحقيقات دانشجويى، دانشكده يرستارى و مامايى شهيد بهشتى، دانشكاه علوم يزشكى تيلان، رشت، ايران

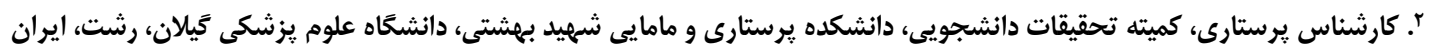

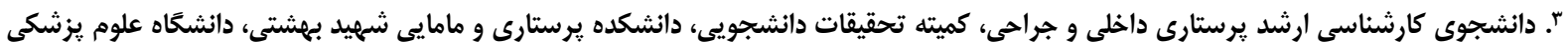
كَيلان، رشت، ايران ع.. دانشجوى كارشناسى ارشد إن يرستارى داخلى و جراحى، كميته تحقيقات دانشجويى، دانشكده يرستارى و مامايى، دانشًاه علوم يزشكى اردبيل، اردبيل،

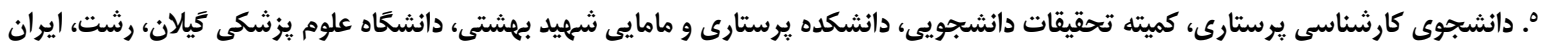

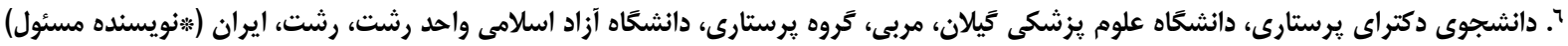




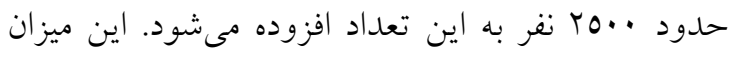

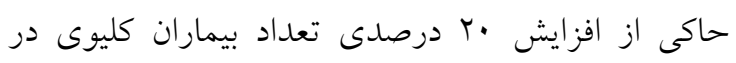

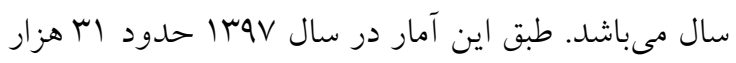

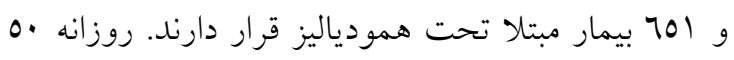
ميليارد تومان براى دياليز بيماران كليوى در كشور هزينه

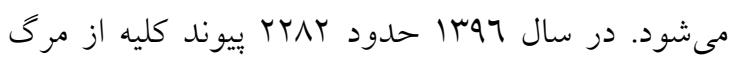
مغزى و فرد زنده صورت كرفته است (IT).

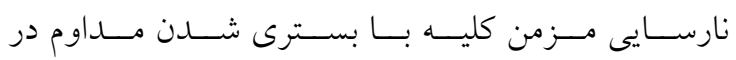

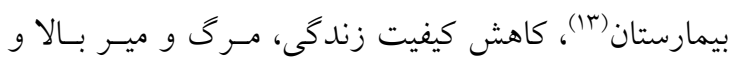

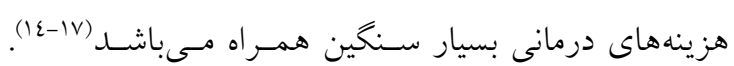

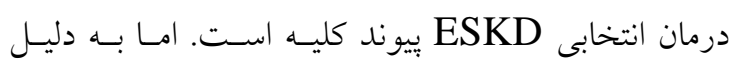

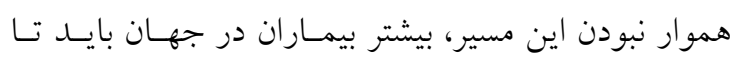

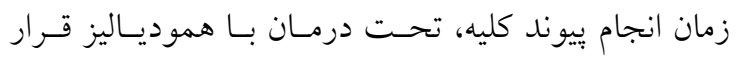

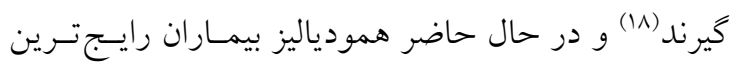

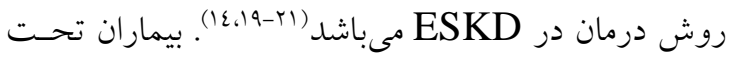

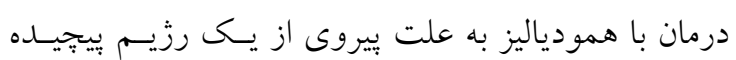
درمانى و تغييرات وسيع و اساسى در سبك زندئى دجئهار

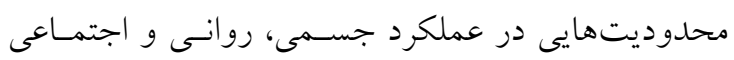
مى گردند (Tr). اين بيماران براى به دست دمائ آوردن ساير نيساز

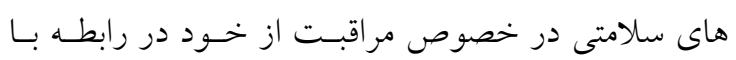
همودياليز، نيازمند توصيههاى روزانه در رابطه با داروهـا، رزيم غذايى، مدت زمان همودياليز و ويزيت توسط ارائسه

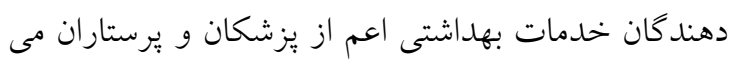

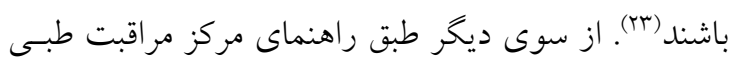

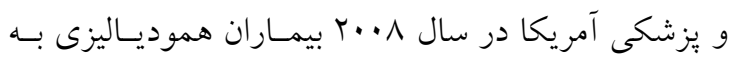

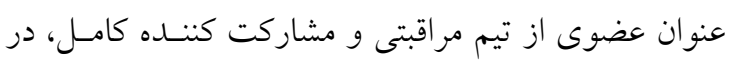

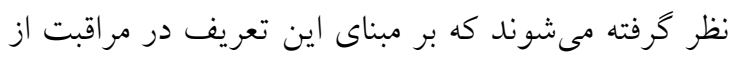

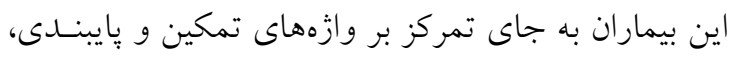

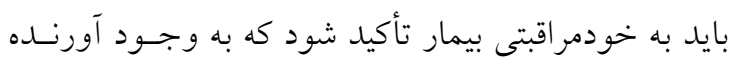

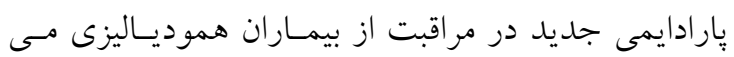

باشد (0).

مراقبت از خود را شامل فعاليتهايى مىداند كـهـ Orem

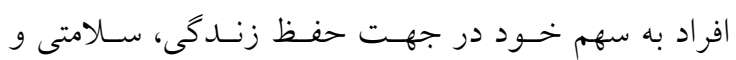

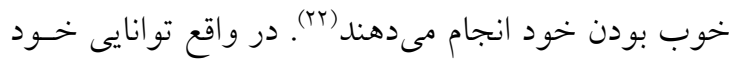

\section{مقدمه}

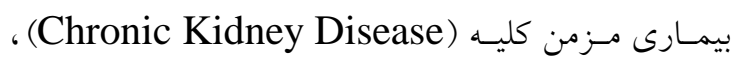

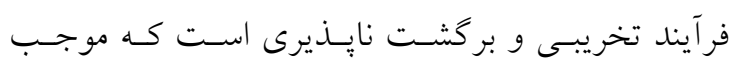

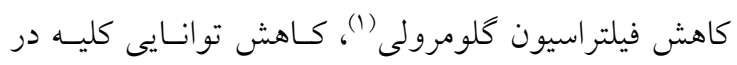
حفظ مايعات و الكتروليتها، برهم زدن تعادل آب و اوره فيتون

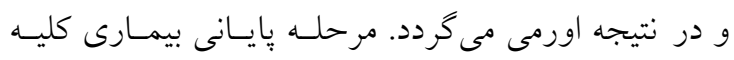
(End Stage Kidney Disease)

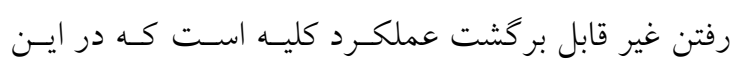

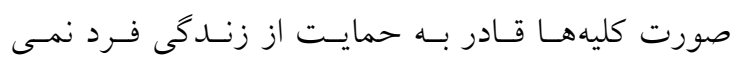

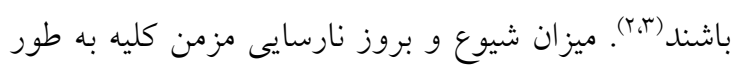

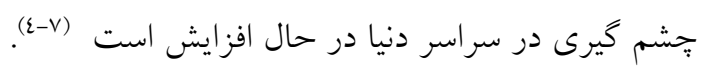

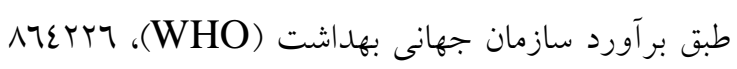
مرى (1/0 درصد مرگ و مير در سرتاسر جهان) در سـال

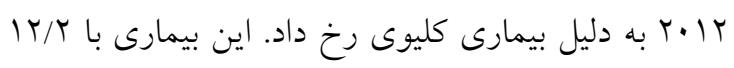

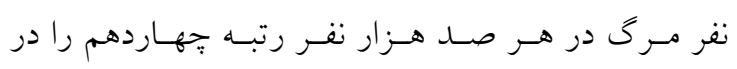

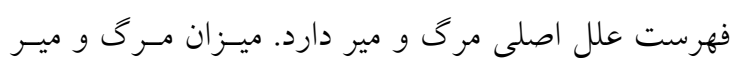

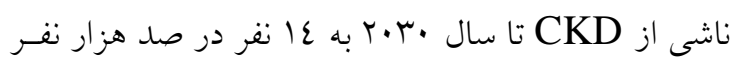

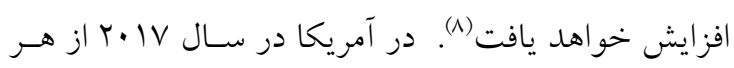

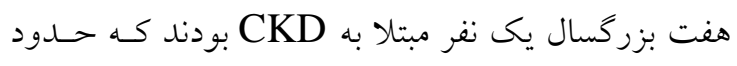

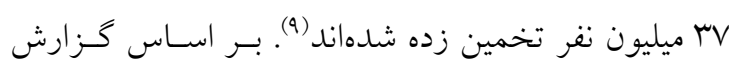

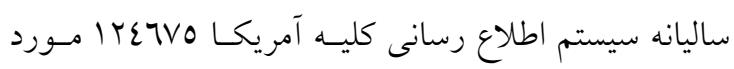

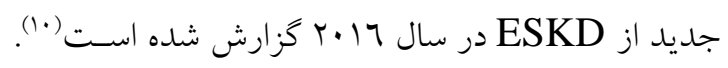

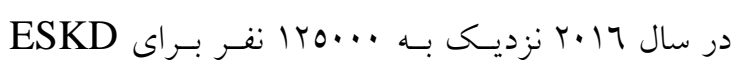

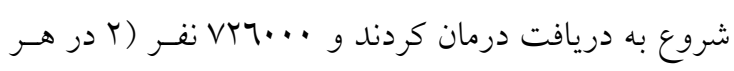

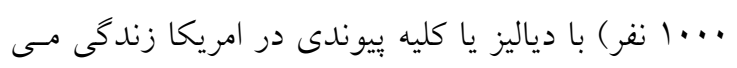
كردند (11).

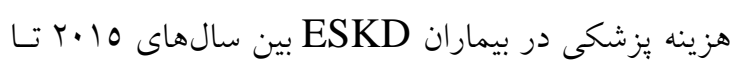

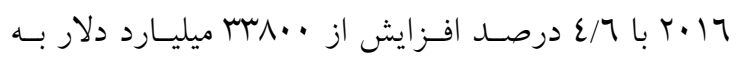

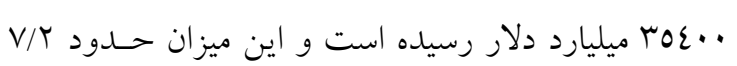

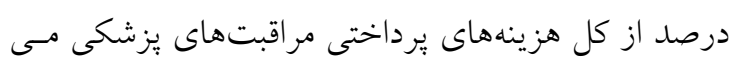

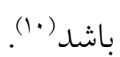
طبق آخرين آمار انجمن حمايت از بيماران كليوى ايران،

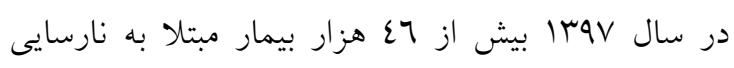

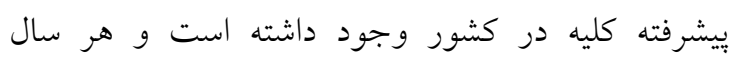


به به ازاى MV بيمار در حال دياليز در اين مركز

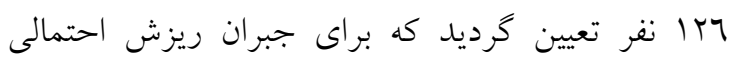

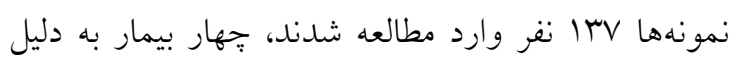
نداشتن تمايل به همكارى و هفت بيمار به دليل داشتن

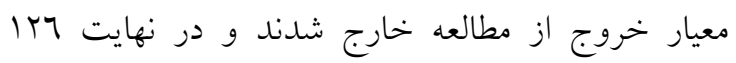

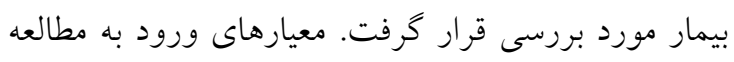

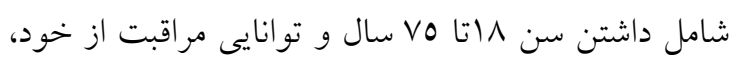

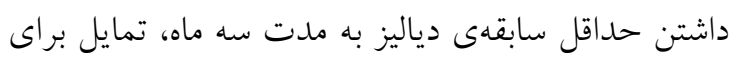
شركت در مطالعه، نداشتن معلوليت جسمى و حركتى،

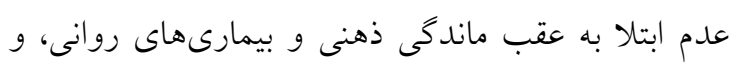

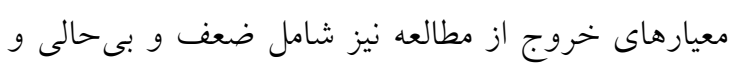
بعىقرارى و انصراف از شركت در مطالعه بودند. به منظور

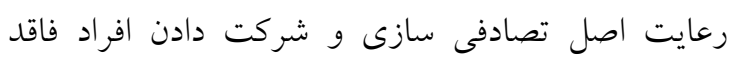

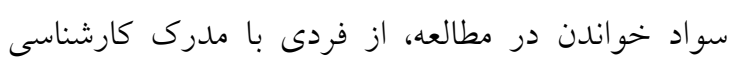

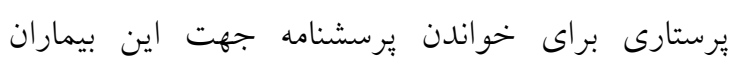

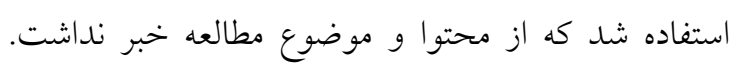

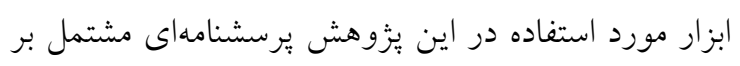

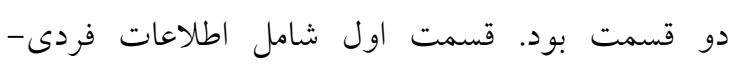
اجتماعى و قسمت دوم يرسشنامهاى شكل تعديل يافته فئه

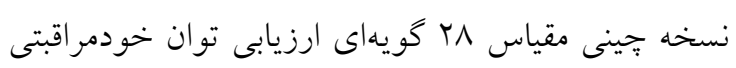

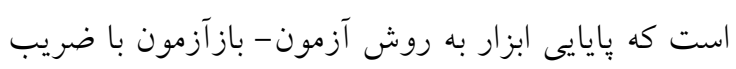

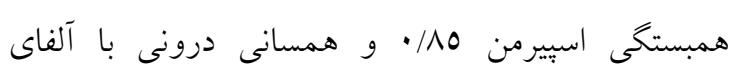

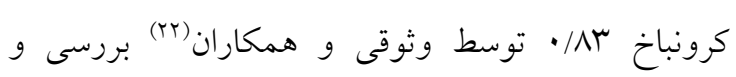
تعيين خرديد.

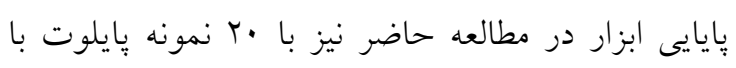

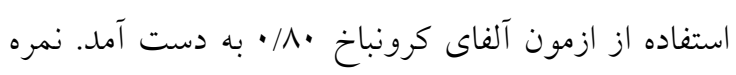
دهى اين يرسشنامه بر اساس مقياس ليكرت بوده و داراى

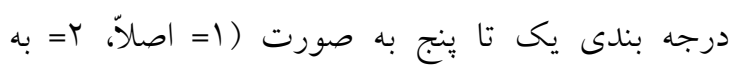

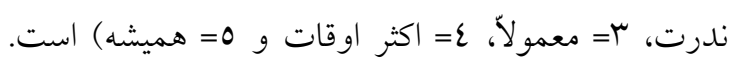

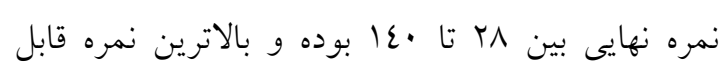
كسب در اين ابزار •عا مىباشد كه كسب نمرهى بالاتر

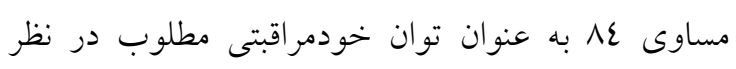

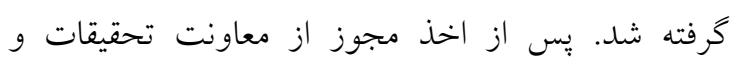

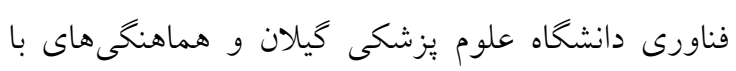

مراقبتى به معنى ظرفيت و قدرت مردم براى رفع نيازهاى

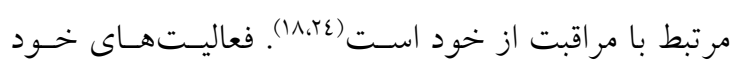

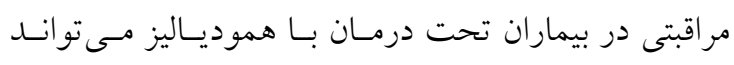

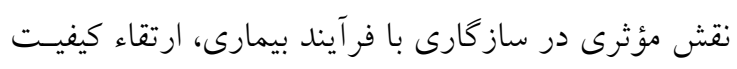

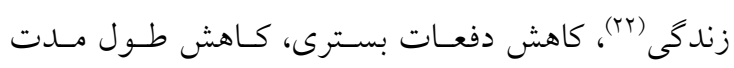

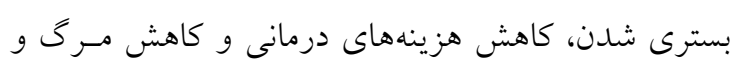
مير آنان ايفا نمايد (0).

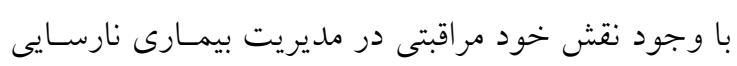

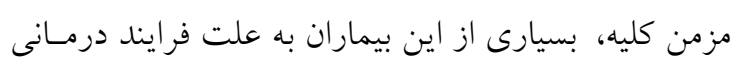

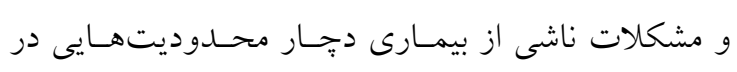

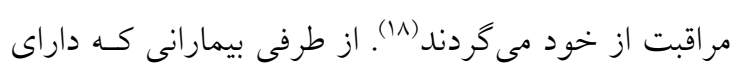

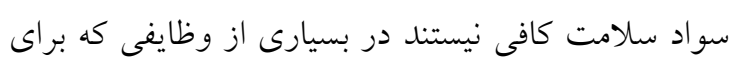

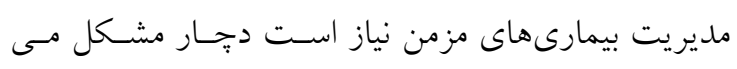

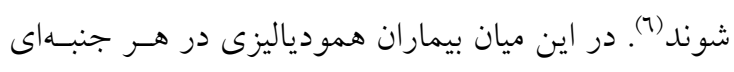

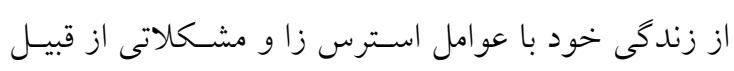

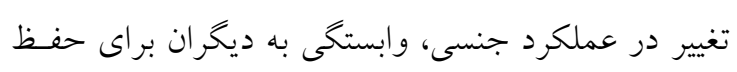

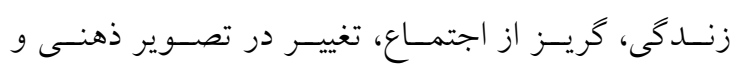

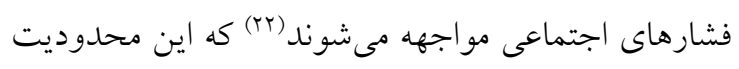

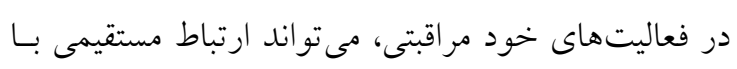

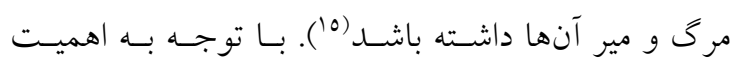

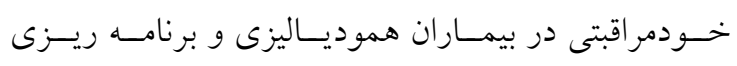

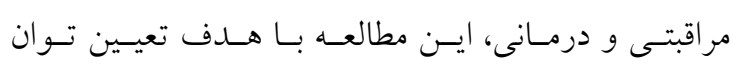

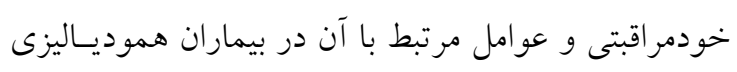

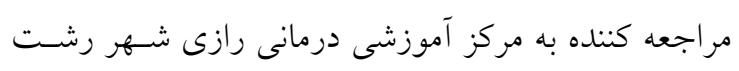

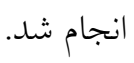

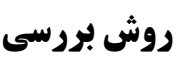

يزوهش حاضر مطالعهاى مقطعى است كه با مجوز كميته

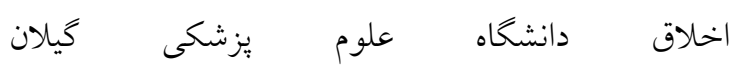
(IR.GUMS.REC.1395.310)

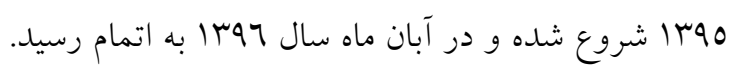
جامعلى مورد يزوهش، بيماران مراجعه كننده به مركز

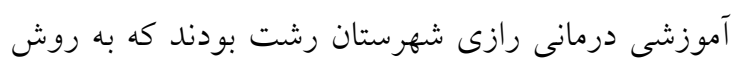

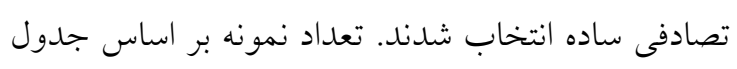


جدول شماره ا: متغيرهاى جمعيت شناختى بيماران

همودياليزى

\begin{tabular}{|c|c|c|}
\hline تعداد (درصد) & \multicolumn{2}{|c|}{ متغير هاى جمعيت شناختى } \\
\hline$V v(71 / 1)$ & مرد & جنسيت \\
\hline$\varepsilon q(r / / q)$ & زن & \\
\hline $19(10 / 1)$ & مجرد & \\
\hline $99(\mathrm{~V} / \mathrm{T})$ & متأهل & وضعيت تأهل \\
\hline $7(\varepsilon / \Lambda)$ & مطلقه - م م & \\
\hline$r(1 / 7)$ & بيوه & \\
\hline$\Lambda \Gamma(70 / 9)$ & زير دييلم & \\
\hline$M r(r o / \varepsilon)$ & ديبلم & سطح تحصيلات \\
\hline $11(\mathrm{~A} / \mathrm{V})$ & دانشگاهى & \\
\hline$r \mu(1 \Lambda / r)$ & بله & مصرف سيكار \\
\hline $\mathrm{V} \wedge(\Lambda \mid / N)$ & 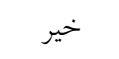 & \\
\hline $11(\Lambda / v)$ & بله & مصرف الكل \\
\hline $110(91 / \%)$ & خير & \\
\hline 1/l / & $=9 / 1$ & ميانخين سنى \\
\hline L TONT & 的 & ميانخين مدت زمان همودياليز \\
\hline
\end{tabular}

واحدهاى ذى ربط، اهداف مطالعه براى افراد واجد

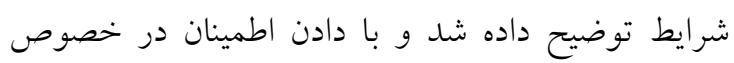

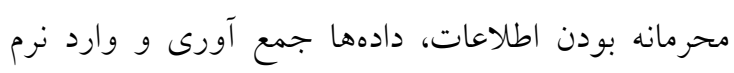

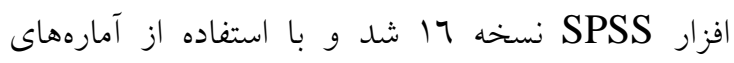

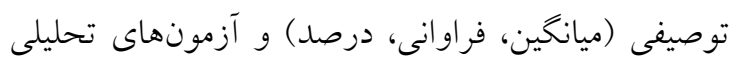

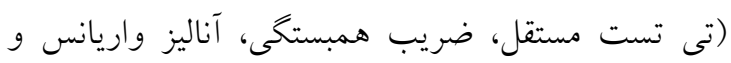
ركرسيون لجستيك) مورد تجزيه و تحليل قرار خرفت.

\section{يافتهها}

نتايج نشـان داد، ميـانخين سـنى افـراد شـركت كنـــه در

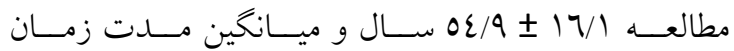

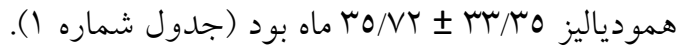

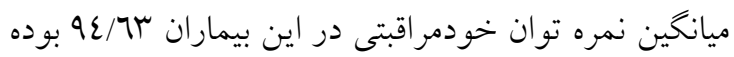

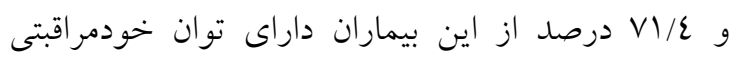
مطلوب بودند (جدول شماره r). ارتباط معنىدارى ميان

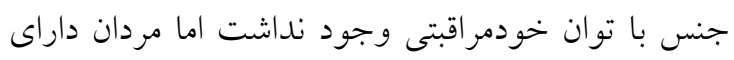
ميانخين نمره توان خودمراقبتى بالاترى نسبت به زئ زنان بودند

جدول شماره r: توان خودمراقبتى بيماران همودياليزى

\begin{tabular}{|c|c|c|c|c|}
\hline ميانخين و انحراف معيار & حداقل & حداكثر & تعداد (درصد) & توان خودمر اقبتى \\
\hline \multirow[t]{2}{*}{$9 \varepsilon / T r \pm r / / 0 V$} & ra & 149 & $\mu(Y \wedge / T)$ & نا مطلوب \\
\hline & & & $q \cdot(V / / \varepsilon)$ & مطلوب \\
\hline
\end{tabular}

ارتباط معنىدارى وجود ندارد. هم:جنين در بررسى ارتباط

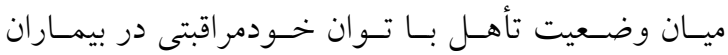
همودياليزى ارتباط معنىدارى ديده نشد.

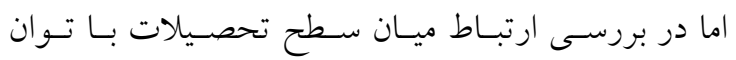

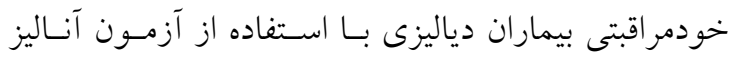

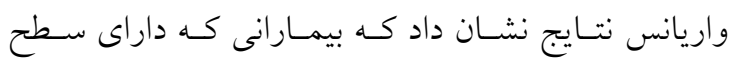
تحصيلات بالاترى هستند، از تـوان خــودمر اقبتى بـالاترى

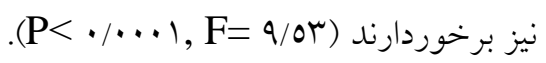
به منظـور تعيسين مهـمتــــين عوامـل تأثيركـذار در تـوان

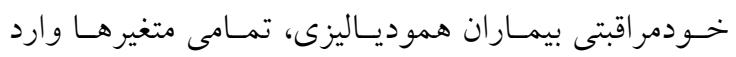

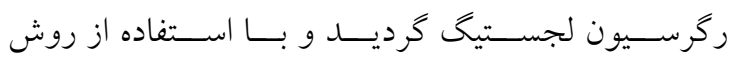

در تجزيه و تحليل دادهها با ضـريب همبسـتخى ييرسـون

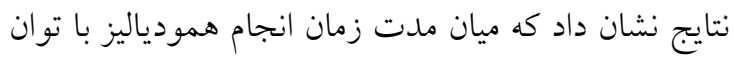

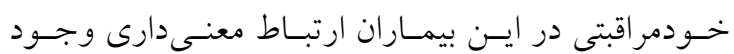
نداشت اما ميـان سـن بــا تـوان خـودمر اقبتى در بيمـاران

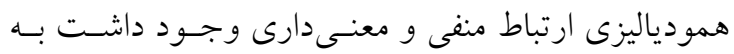

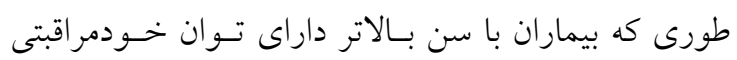

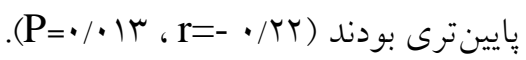

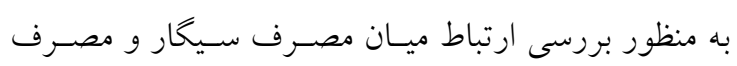

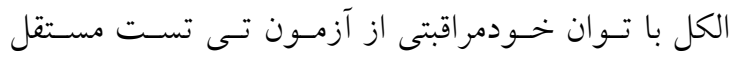

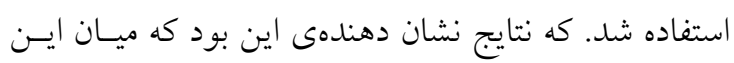

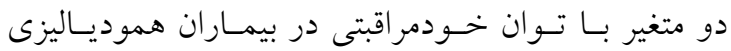


طورى كه هرجه سن بيماران از ميانخين سنى كل بيمـاران

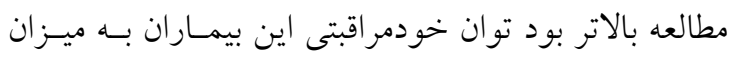

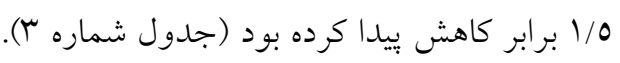

Backward

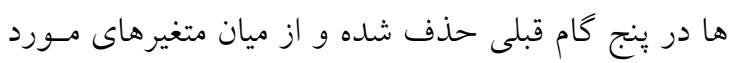

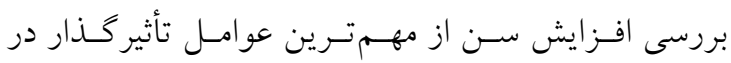

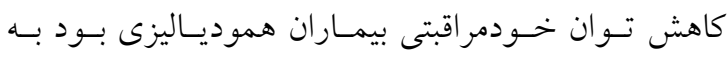

جدول شماره س: برآورد ضرايب رترسيون عوامل مر تبط با توان خودمراقبتى بيماران همودياليزى

\begin{tabular}{|c|c|c|c|c|c|c|c|c|}
\hline \multicolumn{2}{|c|}{ فاصله اعتماد 90٪ } & \multirow[t]{2}{*}{ خظر نسبى } & \multirow{2}{*}{ مقدار احتمال } & \multirow[t]{2}{*}{ درجه آزادى } & \multirow{2}{*}{ آماره آزمون } & \multirow[t]{2}{*}{ خطاى معيار } & \multirow[t]{2}{*}{ ضريب رگرسيون } & \multirow[t]{2}{*}{ متغير } \\
\hline حد بالا & حد بايين & & & & & & & \\
\hline $1 / .11$ & $\cdot \pi \cdot \varepsilon$ & $\cdot / 207$ & .1 .0 & 1 & $r / T V O$ & $. / \varepsilon \mid$. & $-\cdot$ NAT & سن \\
\hline
\end{tabular}

و بالاتر بود در حالى تنها 1\%/9 درصد از بيماران بـا تـوان خودمر اقبتى نـامطلوب داراى سـطح تحصسيلات ديسيلم و

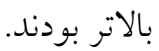

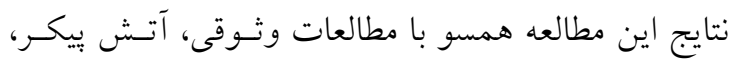
Unsar

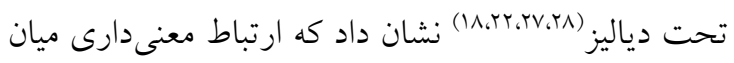
سطح تحصيلات با توان خودمراقتى بيماران تحت درمان

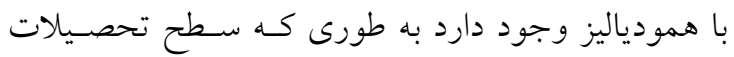
بالاتر با توان خودمراقبتى مطلوبترى همراه بودة. Orem

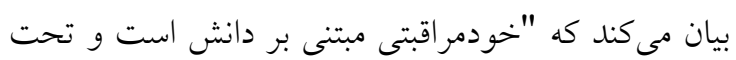

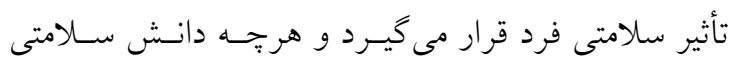

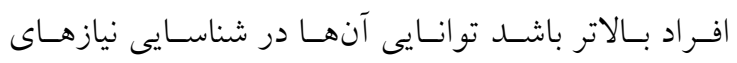

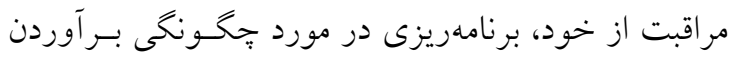
نيازها و قضاوت و تصميم گيرى درباره اولويت بندى نياز

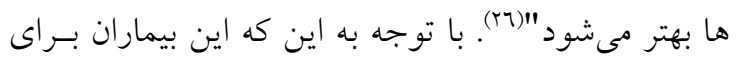

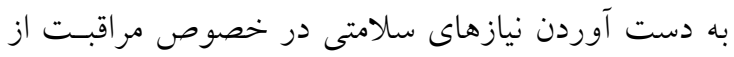

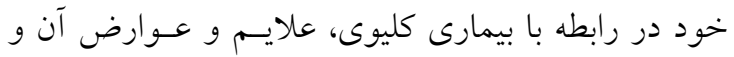

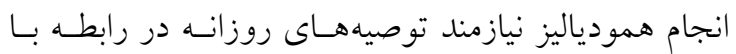
داروها، رزيم غذايى، مدت زمان دياليز و ويزيست توسط

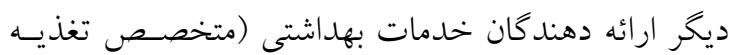

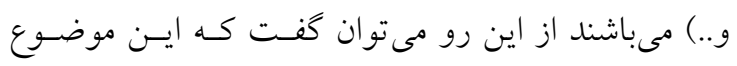

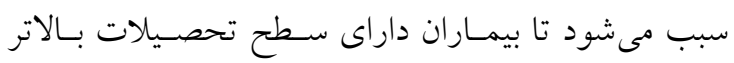
قدرت درى و قضـاوت بهتـرى در تشـخيص و اولويـت بندى نيازهاى خود و تصميم گيرىهاى بهتر در مراقبت از

\section{بحث و نتيجه}

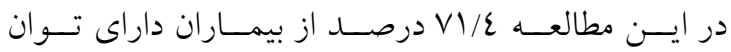
خودمر اقبتى مطلوب بودند. نتـايج ايسن مطالعـه بـا نتـايج

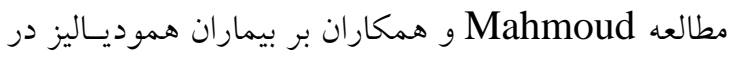
مصر همسو بود(10) و نشان دهندهى اين است كه بيمـاران

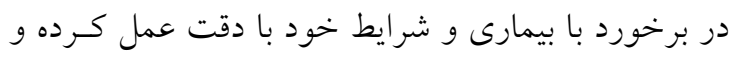

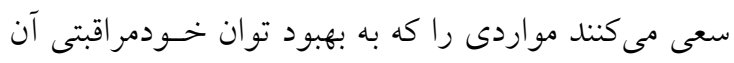

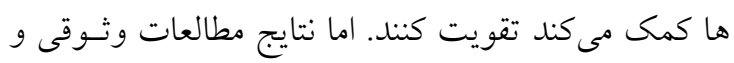

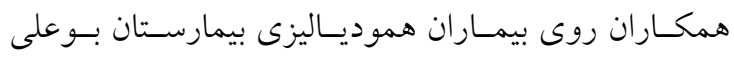

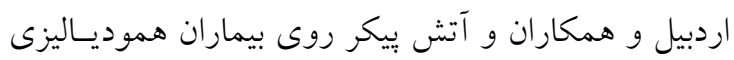

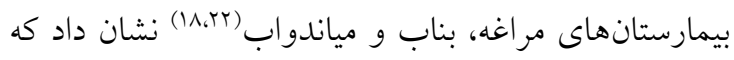
بـهـ ترتيـب ايسن بيمـاران تـوان خهـودمراقبتى متوسـط و نامطلوبى داشتند. وجود ايـن تفـاوت همـان طـور كـه در

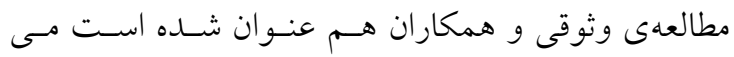
تواند نشـان دهنــدهى نقـش سـطح تحصسيلات در تـوان

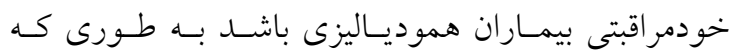
Orem خودمراقبتى افراد تحت تأثير دانش سلامتى آنهـا بـودهه و

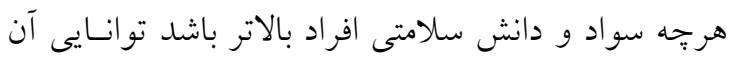

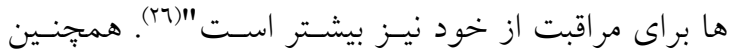

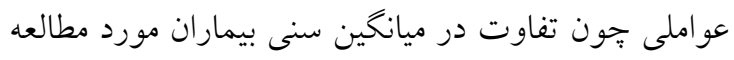

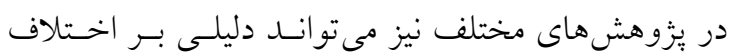
نتايج يزوهش هاى مورد بررسى باشد. 
مى توان كفت كه بالاتر بودن توان خـودمراقبتى در مـردان

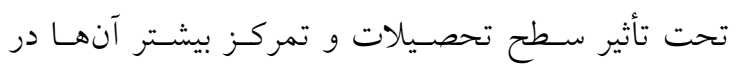

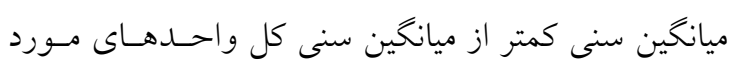

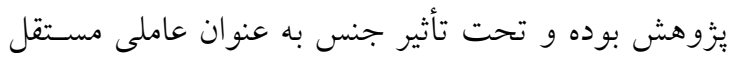

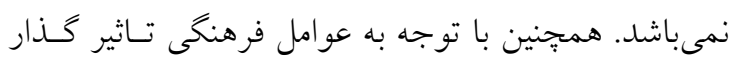

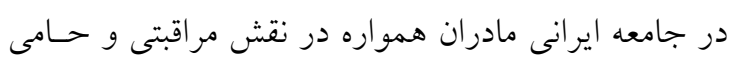
براى اعضاى خانو اده خود ظاهر مى شوند در نتيجه شـايد

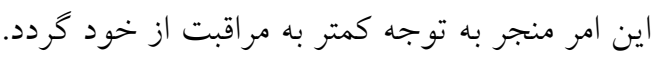
نتايج نشان داد ميان مصرف سيخار، الكل و وضعيت تأهل با توان خودمراقبتى بيماران تحت درمان با همودياليز

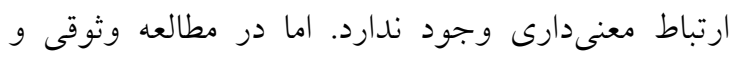

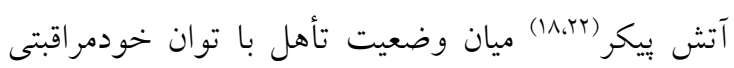

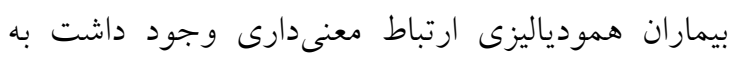
طورى كه بيماران مجرد داراى توان خودمراقبتى بالاترى

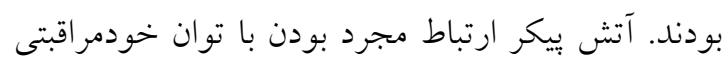

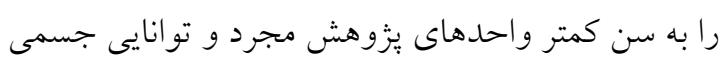

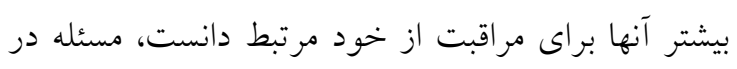

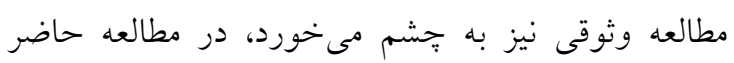
نمره ميانكين خود مراقبتى در افراد مجرد بالاتر از متأهل

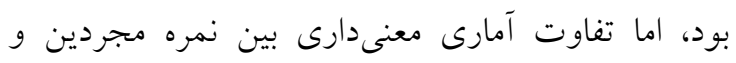
متأهلين ديده نشد. شايد علت آن تفاوت در تعداد افراد

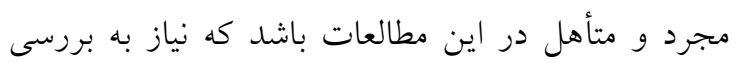
بيشتر و مطالعات جامعتر در اين زمينه را نشان مىدهد دهد.

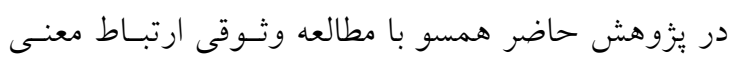

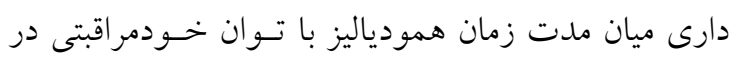

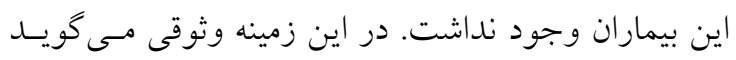

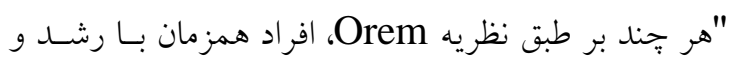
تكامـل و توسـعه توانـايى جسـمانى، دانسش و تجربيـات

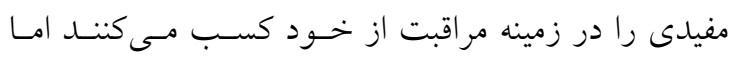
همزمان با افزايش سن و سابقه همودياليز، بيماران مبتلا به

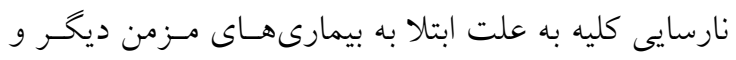

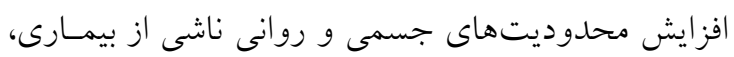
دجار كاهش توانايى جهت مراقبت از خود مى گردند" (Tr).
خود داشته باشند و بنابر اين مى توانند نقش يررنخت ترى در

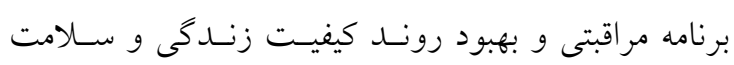

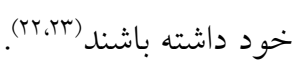

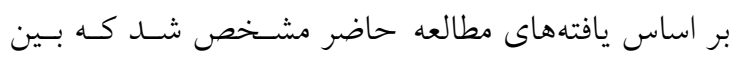

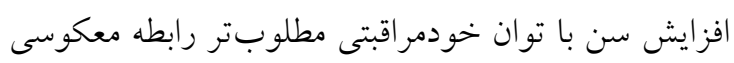
وجود دارد و با بالا رفتن سن توان خودمر اقبتى در بيماران تحت درمان با همودياليز كـاهش مسىيابــ. در ايسن ميـان

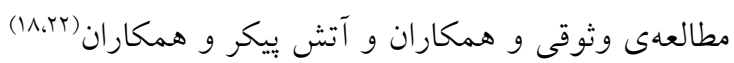

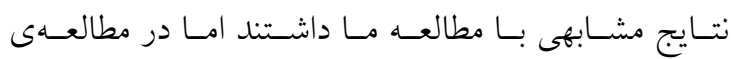
Algarra

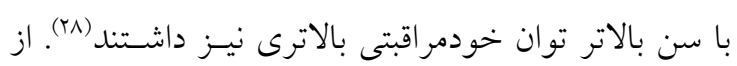

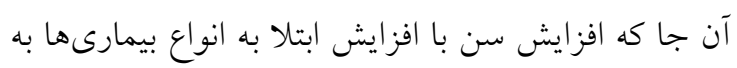

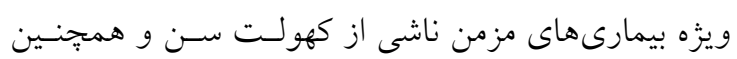

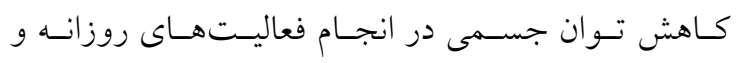

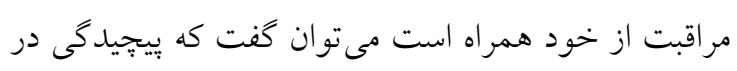

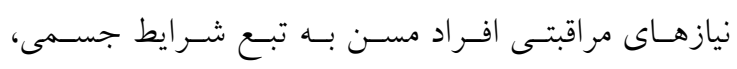

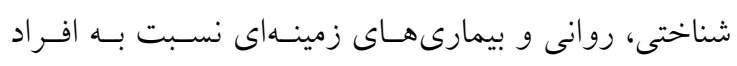

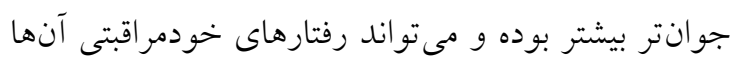

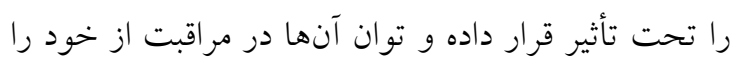

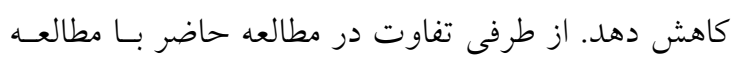
Algarra

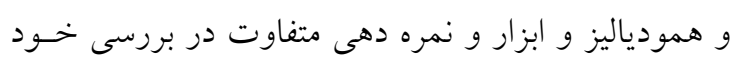

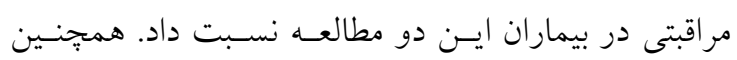

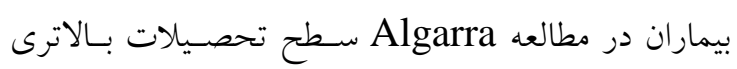
نسبت به مطالعه ما داثتند. در اين مطالعه مشخص شد كـه ارتبـاط معنسىدارى ميـان

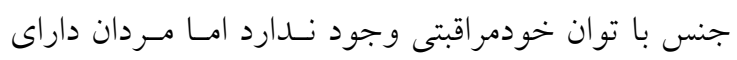

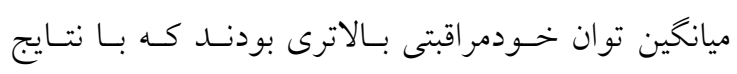

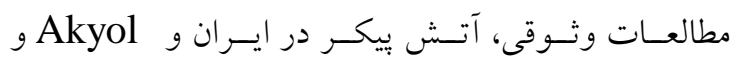
همكاران در تركيه همسو بود (1).r.ra)

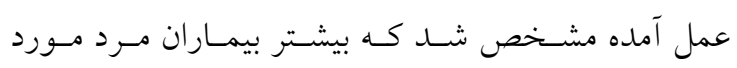

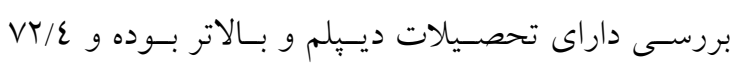

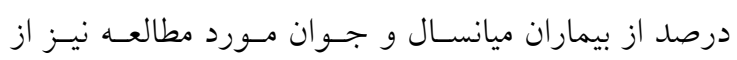


بيشنهاد مى گردد مطالعات نيمه تجربى با محتواى آموزشى جهت افزايش توان خودمراقبتى اين دسته از بيماران در

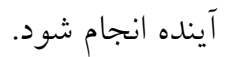

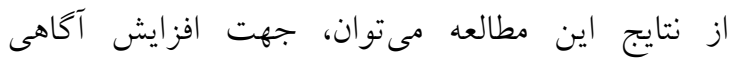

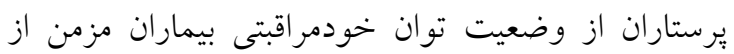

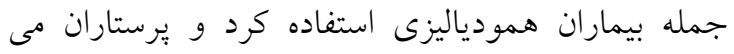
تواند از نتايج اين مطالعه جهت انجام يكى از مهمترين وظايف يرستارى، يعنى آموزش فردى شده به بيمار، بهره

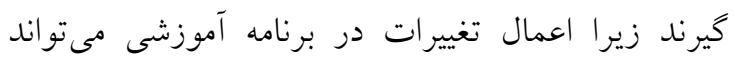
موجب تغيير در وضعيت توانايى خودمراقبتى بيماران

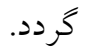

تعارض منافع: هيج گونه تعارض منافع توسط نويسندگان بيان نشده است.

\section{تقدير و تشكر}

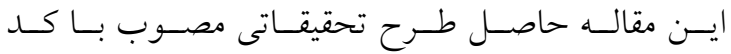

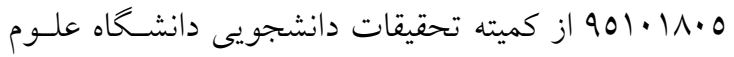
يزشكى خيلان مى باشد. بدين وسيله مراتب سياس خود را

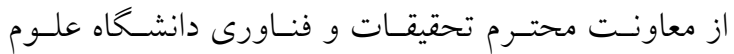
يزشكى كيلان بـه عنـوان حسامى مـالى، معاونـت درمـان دانشخاه علوم يزشكى كيلان و همجينين همكارى مسئولين

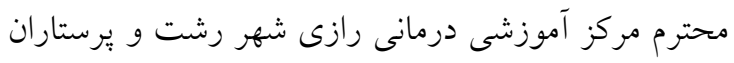
بخش همودياليز اعلام مى داريم.
اخر جهه در مطالعهى حاضر بيشتر بيماران تحت درمـان بـاــا همودياليز داراى توان خودمراقبتى مطلوبى بودند اما نتايج

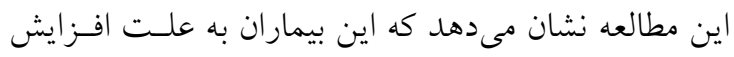

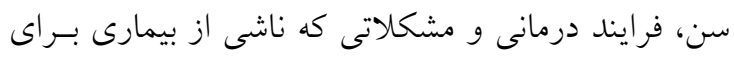

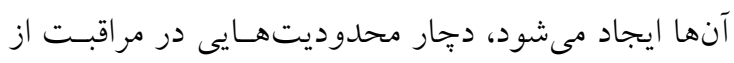

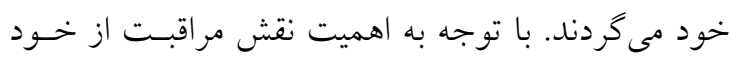

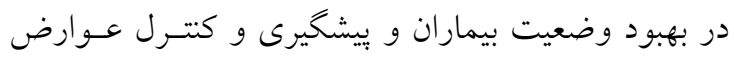

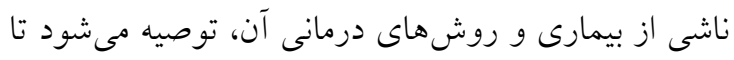
به منظور هرجهه بهتر شدن توان خودمر اقبتى اين بيمـاران،

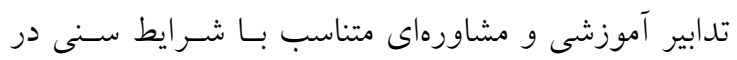

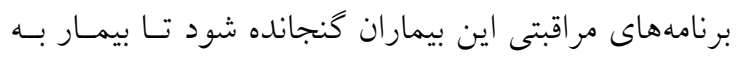
عنوان عضوى از تيم مراقبتى در مر اقبت از خود مشاركت

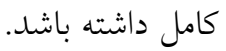
در اين مطالعه براى شركت كنندكانى كه توانيى خواندن

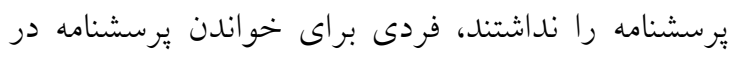

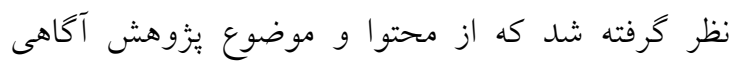

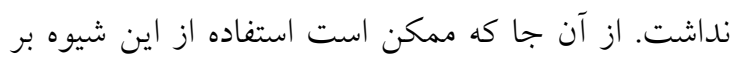
روى درى سئوالات توسط افراد شركت كننده در مطالعه آنه

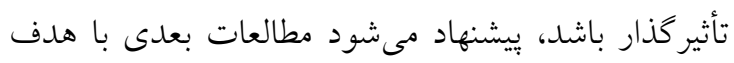

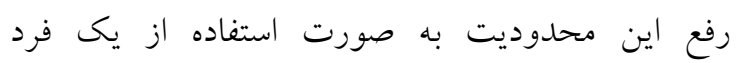

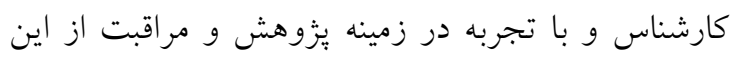

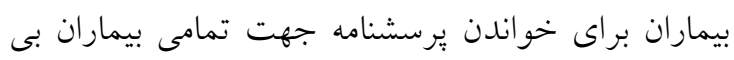

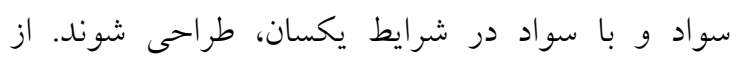

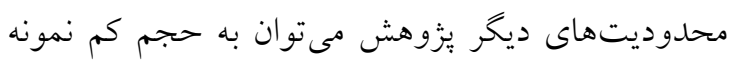

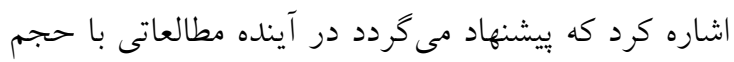

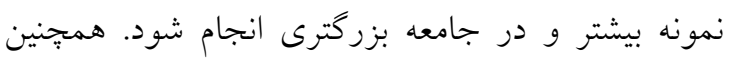

\section{References}

1. Cheever KH, Hinkle JL, Hinkle JL. Brunner \& Suddarth's Textbook of Medical-surgical Nursing. 2014.

2. Yu ZL, Lee VY, Kang AW, Chan S, Foo M, Chan CM, Griva K. Rates of intentional and unintentional nonadherence to peritoneal dialysis regimes and associated factors. PloS one. 2016;11(2):e0149784.

3. Akin S, Mendi B, Ozturk B, Cinper C, Durna Z. Assessment of relationship between self-care and fatigue and loneliness in haemodialysis patients. J Clin Nurs. 2014;23(5-6):856-64.

4. Kara B. Validity and reliability of the Turkish version of the thirst distress scale in patients on hemodialysis. Asian Nurs Res. 2013;7(4):212-8.

5. Browne T, Merighi JR. Barriers to adult hemodialysis patients' self-management of oral medications. Am J Kidney Dis. 2010;56(3):547-57. 
6. Green JA, Mor MK, Shields AM, Sevick MA, Arnold RM, Palevsky PM, Fine MJ, Weisbord SD. Associations of health literacy with dialysis adherence and health resource utilization in patients receiving maintenance hemodialysis. Am J Kidney Dis. 2013;62(1):73-80.

7. Firoozjahi AR, Akbari R, Heidari B, Ghazimirsaeed AM, Hajian K, Satvati J. Evaluation of serum omentin concentration and its association with cardiovascular risk factors in patients undergoing hemodialysis. JOURNAL OF BABOL UNIVERSITY OF MEDICAL SCIENCES (JBUMS). 2015;17(11):28-34. [Persian]

8. Saran R, Robinson B, Abbott KC, Agodoa LY, Bhave N, Bragg-Gresham J, Balkrishnan R, et al. US renal data system 2017 annual data report: epidemiology of kidney disease in the United States. American journal of kidney diseases: the official journal of the National Kidney Foundation. 2018 Mar;71(3 Suppl 1):A7.

9. https://www.kidney.org/news/one-seven-american-adults-estimated-to-have-chronic-kidneydisease.

10. https://www.usrds.org/2018/view/v2_01.aspx

11. Center for Disease Control and Prevention. Chronic Kidney Disease in the United States, 2019. Atlanta, GA: US Department of Health and Human Services, Centers for Disease Control and Prevention. 2019.

12. http://www.irankf.com/.

13. Rayner HC, Zepel L, Fuller DS, Morgenstern H, Karaboyas A, Culleton BF, Mapes DL, Lopes AA, Gillespie BW, Hasegawa T, Saran R. Recovery time, quality of life, and mortality in hemodialysis patients: the Dialysis Outcomes and Practice Patterns Study (DOPPS). Am J Kidney Dis. 2014;64(1):86-94.

14. Sajjadi M, Akbari A, Kianmehr M, Atarodi AR. The relationship between self-care and depression in patients undergoing hemodialysis. The Horizon of Medical Sciences. 2008;14(1):13-7. [Persian]

15. Wang YC, Lin YK. Association between temperature and emergency room visits for cardiorespiratory diseases, metabolic syndrome-related diseases, and accidents in metropolitan Taipei. PloS one. 2014;9(6):e99599.

16. Tao X, Chow SK, Wong FK. A nurse-led case management program on home exercise training for hemodialysis patients: A randomized controlled trial. Int J Nurs Stud. 2015;52(6):1029-41.

17. Kalender N, Tosun N. Determination of the relationship between adequacy of dialysis and quality of life and self-care agency. J Clinl Nurs. 2014;23(5-6):820-8.

18. Atashpeikar S, Jalilazar T, Heidarzadeh M. Self-care ability in hemodialysis patients. J Caring Sci. 2012;1(1):31-5. [Persian]

19. Rahimi F, Gharib A, Beyramijam M, Naseri O. Effect of self-care education on self efficacy in patients undergoing hemodialysis. Life Science Journal. 2014;11(1 SPEC):136-40. [Persian]

20. Bahadori M, Ghavidel F, Mohammadzadeh S, Ravangard R. The effects of an interventional program based on self-care model on health-related quality of life outcomes in hemodialysis patients. J Educ Health Promot. 2014;3:110.

21. Kavosi Z, Khorrami MS, Keshavarz K, Jafari A, Meshkini AH, Safaei HR, Nikfar S. Is Taurolidine-citrate an effective and cost-effective hemodialysis catheter lock solution? A systematic review and cost-effectiveness analysis. Medical journal of the Islamic Republic of Iran. 2016;30(1):313-26. [Perain]

22. Vosoughi N AG, Karimollahi M. The Study of Self- Care Agency in Patients Undergoing Hemodialysis Referred to Boali Hospital of Ardabil in 2013. Scientific Journal of Hamadan Nursing \& Midwifery Faculty. 2015;23(2):24-30. [Persian]

23. Cavanaugh KL, Osborn CY, Tentori F, Rothman RL, Ikizler TA, Wallston KA. Performance of a brief survey to assess health literacy in patients receiving hemodialysis. Clin Kidney J. 2015 10;8(4):462-8.

24. Denyes MJ, Orem DE, Bekel G. Self-care: A foundational science. Nurs Sci Q. 2001;14(1):4854.

25. Mahmoud S, Abd-Elaziz N. Association between health locus of control, self-care and selfefficacy in patients with end stage renal disease undergoing hemodialysis. Life Science Journal. 2015;2(11).

26. Orem DE. Nursing: Concepts of Practice, $6^{\text {th }}$ ed. St Louis. A Harcourt Health. 2001. 
27. Unsar S, Erol O, Mollaoglu M. The self-care agency in dialyzed patients. Dialysis \& transplantation. 2007;36(2):57-70.

28. Algarra AJ, Díaz FJ. Capacidad de autocuidado de los pacientes en diálisis peritoneal: un estudio piloto en Bogotá. Enfermería Global. 2013;12(30): 54-64.

29. Akyol AD, Cetinkaya Y, Bakan G, Yaralı S, Akkuş S. Self-care agency and factors related to this agency among patients with hypertension. J Clin Nurs. 2007;16(4):679-87. 